\title{
Evidence for hypodescent and racial hierarchy in the categorization and perception of biracial individuals.
}

\section{Citation}

Ho, Arnold K., Jim Sidanius, Daniel T. Levin, and Mahzarin R. Banaji. 2011. “Evidence for Hypodescent and Racial Hierarchy in the Categorization and Perception of Biracial Individuals." Journal of Personality and Social Psychology 100, no. 3: 492-506.

\section{Published Version}

doi:10.1037/a0021562

\section{Permanent link}

http://nrs.harvard.edu/urn-3:HUL.InstRepos:14369672

\section{Terms of Use}

This article was downloaded from Harvard University's DASH repository, and is made available under the terms and conditions applicable to Open Access Policy Articles, as set forth at http:// nrs.harvard.edu/urn-3:HUL.InstRepos:dash.current.terms-of-use\#OAP

\section{Share Your Story}

The Harvard community has made this article openly available.

Please share how this access benefits you. Submit a story.

\section{Accessibility}


Running head: HYPODESCENT AND RACIAL HIERARCHY

\title{
In Press - Journal of Personality and Social Psychology
}

\section{Note: This is the author's final copy following acceptance for publication but prior to final copy-editing}

Evidence for Hypodescent and Racial Hierarchy in the Categorization and Perception of Biracial

\author{
Individuals \\ Arnold K. Ho \\ Harvard University \\ Jim Sidanius \\ Harvard University \\ Daniel T. Levin \\ Vanderbilt University \\ Mahzarin R. Banaji \\ Harvard University
}

Address correspondence to:

Arnold K. Ho

Department of Psychology

Harvard University

33 Kirkland Street

Cambridge, MA 02138

Email: arnoldho@fas.harvard.edu 


\begin{abstract}
Individuals who qualify equally for membership in two racial groups provide a rare window into social categorization and perception. In five experiments, we tested the extent to which a rule of hypodescent, whereby biracial individuals are assigned the status of their socially subordinate parent group, would govern perceptions of Asian-White and Black-White targets. In Experiment 1, in spite of posing explicit questions concerning Asian-White and Black-White targets, hypodescent was observed in both cases and more strongly in Black-White social categorization. Experiments 2A and 2B used a speeded response task and again revealed evidence of hypodescent in both cases, and a stronger effect in the Black-White target condition. In Experiments 3A and 3B, social perception was studied using a face morphing task. Participants required a face to be lower in proportion minority to be perceived as minority than in proportion White to be perceived as Whites. Again, the threshold for being perceived as White was higher for Black-White than Asian-White targets. An independent categorization task in Experiment 3B further confirmed the rule of hypodescent and variation in it that reflected the current racial hierarchy in the United States. These results documenting biases in the social categorization and perception of biracials have implications for resistance to change in the American racial hierarchy.
\end{abstract}


Evidence for Hypodescent and Racial Hierarchy in the Categorization and Perception of Biracial Individuals

The “mixing of races” in America provides a natural laboratory for measuring perceptions of new racial identities that diverge from older and simpler notions of race purity (Shih \& Sanchez, 2009). While social psychologists have studied how humans think about ingroups and outgroups for decades, relatively little is known about the perception of individuals who, by the fact that they embody mixtures of social identities within a single individual, blur traditional group boundaries. Such individuals provide intriguing test cases for social categorization and social perception. We focus on one aspect of such mixtures by studying how humans who meld two seemingly distinct racial groups are categorized and perceived and thereby test how socially meaningful lines that determine inclusion into desired group memberships are drawn. Fundamentally, the categorization and perception of biracials and multiracials more broadly can reveal how culturally entrenched social categories and norms guide, even limit, social perception.

From a socio-structural perspective, miscegenation and biracial identity have profound implications for understanding the stability and permeability of extant racial group boundaries. In the United States, there is a clear and consensually agreed upon racial status hierarchy members of dominant and subordinate groups alike agree that Whites have the highest social status, followed by Asians, Latinos, and Blacks (see Fang, Sidanius, \& Pratto, 1998; Kahn, Ho, Sidanius, \& Pratto, 2009; Sidanius \& Pratto, 1999, pp. 52-53). However, many have argued that the increasing rate of interracial dating and marriage between racial minorities and Whites, and resulting patterns of biracial identification of their offspring, will lead to a fundamental change in the American racial hierarchy (e.g., Alba \& Nee, 2003; Lee \& Bean, 2004; 2007a; 2007b; Sears 
\& Savalei, 2006; Thornton, 2009). For example, Lee and Bean (2004) suggest that "based on patterns of immigration, intermarriage, and racial/multiracial identification,..., Latinos and Asians may enjoy the option to view themselves as almost white or even white, and consequently, participate in a new color line that is still somewhat exclusionary of blacks.” Others like Thornton (2009) have documented how the mainstream media perceives the significance of multiracial identification: "For mainstream [news] papers, we are in a new era, sans racial determinants, and in this context multiracial people embody a color-blind America...” These sentiments assume that biracials will be accepted as part of their dominant parent group, and not limited by their minority parent group status. However, are biracial targets perceived accurately to be equal members of both parent groups, or more in terms of their dominant or subordinate group lineage? The five experiments reported here are aimed at addressing this question.

\section{Historical Treatment of Biracial Individuals}

A review of how biracial individuals have been treated historically gives pause to the assumption that biracial Asian-White and Latino-White individuals will be accorded the status of Whites; biracials in the United States and elsewhere have frequently occupied a marginal position in society (Davis, 1991). Interestingly, many biracial groups (e.g., the AboriginalWhites (Metis) of Canada, Indian-Whites of India, Korean-Whites of Korea, and the Vietnamese-Whites of Vietnam) are perceived as having lower status than both of their parent groups, whereas groups such as the "Coloured” population of South Africa, and the mixed-race populations of South America have come to adopt an intermediate status above their subordinate parent group, but below dominant Whites (Davis, 1991; Sidanius, Peña, \& Sawyer, 2001). There have been only a few cases where mixed-race individuals have achieved equal status or the 
highest status in their respective racial hierarchies. The Native Hawaiian (Polynesian)-WhiteAsian multiracials of Hawaii are believed to have the status of Whites, while the Mestizos of Mexico and Mulattoes of Haiti occupied the highest status in their societies. Such recognition did not come easily; in the Mexican and Haitian cases, a political revolution was the path to high status (Davis, 1991).

In the United States, treatment of mixed-race individuals (Black-White biracials in particular) has historically been governed by a rule of hypodescent, or the “one-drop” rule. This rule, which varied somewhat from state to state, subjugated biracial Black-White individuals to the severe legal and social discrimination faced by their Black ancestors. For example, an early statute (passed in 1662) governing how Black-White “mulattoes” were to be treated in Virginia held that "children got by an Englishman upon a negro woman... shall be held bond or free only according to the condition of the mother (Hickman, 1997, p. 1175).” Beginning in the 1700s, and continuing through the $20^{\text {th }}$ century, many states adopted a "fractional, blood-borne approach” to legally define who was Black (Hickman, 1997). Some states (e.g., Alabama) held that one drop of “Negro” blood rendered a person Black, while others (e.g., Missouri) used fractions such as one-eighth to define Black-White biracials as Black.

As recently as 1985, the Louisiana Fourth Circuit Court of Appeals ruled that the greatgreat-great-great granddaughter of a White French planter and his Black mistress could not identify herself as White (Jane Doe v. State of Louisiana; Davis, 1991). The descendent of this interracial affair, Susie Phipps, was denied a passport because she indicated that she was White while her birth certificate states she is “colored.” The court held that regardless of how Phipps wished to racially identify, the official designation of her race could not be changed because the evidence showed that it was recorded correctly. In 1986, the Louisiana Supreme Court declined 
to review the decision, noting that it concurred with the court of appeals, and the U.S. Supreme Court dismissed the appeal in the same year. Even in our own time, the highest courts in the land have not only upheld the one-drop rule, but also indicated that multiracial individuals cannot chose their identity but rather must be classified as members of the lesser socially advantaged group.

\section{Empirical Studies of Biracials: Identification, Categorization, and Perception}

By focusing on how social perceivers categorize biracial targets, the current experiments expand on the scant empirical literature documenting the social perception of mixed-race individuals (Shih \& Sanchez, 2009), using both explicit verbal reports of belongingness and perceptual judgments of fit with the parent categories. Previous research, taking the target's perspective, has examined how mixed-race individuals identify themselves (i.e., in monoracial or multiracial terms) and how the parents of multiracials identify their children. As recently as the early 1990s, sociologists found that a rule of hypodescent prevailed in Black-White biracials' self-identity (e.g., Waters, 1991). More recently, Roth (2005) found that many Black-White multiracial families use interracial identities for their children, an indication that they do not feel as confined by a rule of hypodescent. Individuals of Asian-White and Latino-White descent feel even more at liberty to identify as multiracial rather than as minority (Lee \& Bean, 2004; 2007a; 2007b; Roth, 2005).

Others have examined how context influences biracial self-identity, demonstrating the effects of parental socialization, regional values, and the biracial's assessment of how others view them (e.g., Brunsma \& Rockquemore, 2001; Brunsma, 2006; Harris \& Sim, 2002). The finding that context matters and that biracials identify their own race in accord with their 
perception of how others view them provoked this study of how mixed-race individuals are categorized and perceived.

In contrast to a small literature exploring self-identification, we know of only a few studies that have explored how mixed-race individuals are categorized by others - i.e., whether they are regarded more as members of their dominant or subordinate parent group - and these have produced inconsistent results. Hirschfield (1995) showed that both American adults and children reason according to a rule of hypodescent, albeit in different ways. Children tend to apply a rule of hypodescent more strongly than adults when it comes to judging physical appearance (i.e., what physical appearance will the child of a mixed-race couple assume?), while adults are more likely to use hypodescent when explicitly judging a target individual's category membership (i.e., should the mixed-race child be labeled as Black or White?). In contrast, Peery and Bodenhausen (2008) found that participants were most likely to describe mixed-race BlackWhite targets as Black in a reflexive categorization task (i.e., when participants had to decide whether targets were Black or White under time pressure), but not so in an explicit task (i.e., when participants had to decide whether targets were Black, White, or multiracial by typing their choice or choosing among labels without time pressure). Thus, the findings concerning explicit categorizations of biracials in the 1990s, when Hirschfield reported his studies, and the latter half of the current decade, in Peery and Bodenhausen’s work, diverge. Furthermore, Peery and Bodenhausen focused their statistical significance testing on moderators of racial categorization, rather than on hypodescent per se. That is, they significance tested the rate of "Black" categorizations as a function of whether participants saw pictures of the biracial targets' parents (biological information) or were given information about how racially diverse the targets’ environment was (cultural information). While it appears that the proportion of "Black" 
categorizations was greater than the proportion of "White," "both," and "neither"

categorizations, this was not significance tested. Building on these previous studies, the present paper will examine whether hypodescent, if observed, operates on an explicit level of social categorization as well as on a reflexive/implicit level. We will also focus our statistical tests on the frequency of racial minority categorizations versus majority group (i.e., White) categorizations. $^{1}$

In the present experiments, we thoroughly and systematically test whether a rule of hypodescent operates in the categorization and perception of Black-White biracials, and for the first time, test whether the rule generalizes to another biracial group. Across experiments, we vary whether the biracial target is seen, whether the ratio of minority to White background is given, and whether the participant is given the chance to respond deliberately. The range of methods and modes of responding represented across experiments allows us to assess how pervasive the rule of hypodescent is. That is, we will be able to assess whether unseen biracial targets are categorized according to a rule of hypodescent, or if instead, hypodescent only operates in the direct visual perception of biracials. Under circumstances in which the visual perception of biracials is involved, these experiments will reveal whether different thresholds apply to being perceived as minority or White (i.e., whether there is a higher threshold for being perceived as White). In addition, we examine if a rule of hypodescent only emerges when automatic modes of responding are required (e.g., Peery \& Bodenhausen, 2008), or if controlled responses to biracial targets also reveals hypodescent. Finally, we test the use of hypodescent in the Asian-White context to examine whether the rule of hypodescent is used to judge biracials outside the Black-White context.

Given the longstanding rule of hypodescent as applied to Black-White individuals in the 
United States, we test whether hypodescent would hold for Black-White targets under a variety of conditions, ranging from the most explicit to more implicit and from tasks that require social categorization of hypothetical targets to those that require direct visual perception of targets. In the first study, we created the strongest condition possible to eliminate the emergence of hypodescent by posing highly explicit questions. If, under such conditions, hypodescent is obtained, it will point to the strength of the belief that such individuals belong more to the lower status parent group.

The predictions concerning how Asian-White targets would be categorized are less obvious, given that this case is tested here for the first time. If the relatively flexible identities Asian Americans appear to experience (Lee and Bean, 2007b) are reflective of how they are categorized, then hypodescent should not hold for Asian-White biracials. However, if the continuing association of Asian Americans with the concept "foreign” (Cheryan \& Monin, 2005; Devos \& Banaji, 2006) guides how Asian-White targets are perceived, we might find that the rule of hypodescent is applied to them as well. It is important to note that we are not equating hypodescent with a strict “one-drop of blood” rule. Even at the point of American history when the “one drop” rule was most prevalent, many states used different percentages of Black ancestry to determine who was Black.

\section{Overview of the Experiments}

Experiment 1 examines the social categorization of mixed-race targets explicitly, using survey questions directed at testing whether mixed-race targets are reported to be more minority (Asian or Black) or majority (White). In doing so, it tests whether hypodescent has gone “undercover" along with other racial attitudes in contemporary America. Experiments 2A and 2B employed a speeded response task in which we presented family trees and measured the 
relative acceptance of minority and majority racial labels for biracial targets. Experiments 3A and 3B used a face morphing procedure to examine whether biracials are more readily perceived as White or as minority, and whether Black-White targets are less readily perceived as White than Asian-White targets. Experiment 3B also employed a speeded categorization task to examine how Asian-White and Black-White biracials along the minority-White continuum are categorized. Unlike the social categorization tasks in Experiments 1 and 2, which asked participants to categorize targets based on background demographic information, Experiment 3 involved the direct visual perception of biracial targets. The use of four distinct methods to capture perceptions of Black-White biracials, and the examination of perceptions of Asian-White biracials, allows us to test how general and pervasive the rule of hypodescent is.

\section{Experiment 1: A Blatant Test of Hypodescent}

In Experiment 1, we examined in the most direct way possible, whether participants regarded the children of mixed-race parentage - in which one or two grandparents were White and the others were minority (Black or Asian) - to be more White or minority. In doing so, we were able to test whether mixed-race targets were categorized in accordance with a rule of hypodescent, and to assess whether a rule of hypodescent, if evident, would apply differentially to Asian-White targets and Black-White targets. The method we used clearly specified the target's racial background, leaving no doubt when the target was equally White and minority in genetic make-up. Given the clarity of this specification, hypodescent should be unlikely; any evidence for it that emerges in such circumstances where the most obvious answer would be ‘equally White and Black (or Asian)’ would provide valuable evidence for the presence of hypodescent. 


\section{Participants}

Two hundred and seventeen participants were recruited around the campus of a university in New England and received candy in return for participation. The ethnic makeup consisted of 116 Caucasian/Whites, 43 Asian/Asian American/Pacific Islanders, 6 African American/Blacks, 8 Latino/Hispanics, 3 Middle Eastern, 1 Native American, 25 Biracial/mixed race, 9 “other,” and 6 who did not report their ethnicity. Six participants did not indicate their race. One hundred and nineteen were female, 91 male, and 7 did not report their gender. The average age was 23.3 $(S D=9.86)$, excluding six participants who did not indicate their age. Since these data were not collected through a research study pool and were collected during the summer, the sample is not composed of only students from the university.

\section{Measures}

Hypodescent. A between subjects design was used such that participants only rated Asian-White or Black-White targets, but not both. Thus, participants in the Asian-White condition responded to two items: 1) "Imagine a child with 2 Asian grandparents and 2 White grandparents. To what extent do you consider this child to be Asian or White?” and 2) “Imagine a child with 1 Asian grandparent and 3 White grandparents. To what extent do you consider this child to be Asian or White?” Participants responded on a 7 point scale, with $1=$ Completely Asian, 2 = Predominantly Asian, 3 = Somewhat more Asian than White, $4=$ Equally Asian and White, 5 = Somewhat more White than Asian, $6=$ Predominantly White, and $7=$ Completely White. In the Black-White condition, the label "Black” replaced the label "Asian” in the question and response options. These items were presented without any pictures of the targets. 
We conducted one-sample t-tests to determine the extent to which the ratings of biracial targets departed from the hypodescent item scale mid-point (4), which read, “equally Asian (or Black) and White.” Aggregating the responses to Asian-White and Black-White targets, we found a reliable deviation from the mid-point in judging minority-White targets such that they were regarded to be relatively more minority than White $(m=3.82, S D=.57, t(216)=-4.49, p<$ $.001, r=.29)$. Moreover, the skew of this sample distribution was statistically significant $(z=-$ 10.64, $p<.001$ ), indicating the distribution of responses significantly leaned toward hypodescent. Decomposing this result by target minority group shows that the rating of both half-Asian targets $(m=3.86 ; S D=.45, t(113)=-3.11, p<.01, r=.28)$ and half-Black targets $(m$ $=3.77 ; S D=.69, t(102)=-3.31, p<.01, r=.31$ ) were significant departures from the midpoint. A direct comparison of the mean ratings for half-Asians and Blacks did not reveal any significant difference $(t(215)=1.18, p=.24)$. However, comparison of the mean rating for quarter-Asians $(m=5.13, S D=.85)$ and quarter-Blacks $(m=4.92, S D=1.01)$ produced a marginally significant difference $(t(215)=1.66, p=.10, r=.11)$, such that quarter-Blacks were categorized as more minority.

Finally, we wanted to see if White and non-White participants evaluated these four biracial targets in the same way - To do so, we conducted four one-way analyses of variance on ratings of half-Asians, half-Blacks, quarter-Asians, and quarter-Blacks, with participant race as a between-subjects factor. This revealed that Whites and non-Whites rated these biracial targets similarly, with one exception. Whites’ ratings did not diverge from non-Whites' ratings for halfBlacks (White $m=3.81$, $S D=.53$ vs. non-White $m=3.72, S D=.89 ; F(1,101)=.46, p=.50, r$ $=.07$ ), half-Asians (White $m=3.82, S D=.43$ vs. non-White $m=3.90, S D=.47 ; F(1,112)=$ $.81, p=.37, r=.08$ ), or quarter-Asians (White $m=5.08, S D=.95$ vs. non-White $m=5.18$, $S D=$ 
$.76 ; F(1,112)=.40, p=.53, r=.06)$. Interestingly, Whites $(m=5.08, S D=.84)$ rated quarterBlacks as relatively more White than non-Whites $(m=4.67, S D=1.20)$ did $(F(1,101)=4.17, p$ $<.05, r=.20)$.

To our surprise, even though we specified the race of each target’s grandparents, giving participants the clear option of reporting that the target was equally White and minority when half the grandparents were minority, we found evidence of hypodescent. Experiment 1 showed that both half Asian-White and half Black-White targets are categorized as relatively more minority than White, and both biracial groups were categorized as equally minority. In addition, the degree of hypodescent observed for the two biracial groups was consistent with the order of the extant racial hierarchy, such that quarter-Black-White targets were categorized as relatively more minority than quarter-Asian-White targets. Thus, when there was a clear standard for what a neutral response would be - in the case of questions concerning half minority-White targets participants in our between subjects design rated half-Asian and half-Black targets almost identically. Where the standard was not as clear - e.g., do you rate a quarter Black target as “Somewhat more White than Black" or "Predominantly White”? - a difference emerged in the expected direction.

\section{Experiment 2A: A Test of the Automaticity of Hypodescent}

While Experiment 1 demonstrated that hypodescent occurs for both half-Asian and halfBlack targets, it only hints at the possibility of greater hypodescent for Black-White targets, or a pattern of hypodescent that is consistent with the structure of the current racial hierarchy. Furthermore, while it is notable that we obtained evidence of hypodescent using such a direct measure, the effect sizes were not very large. This may be due in part to the effect of social desirability in responding to controlled explicit questions about mixed-race targets. Thus, we 
wanted to examine whether speeded judgments of biracial targets would produce bigger hypodescent effects and reveal a racial hierarchy in hypodescent more clearly. To do so, we designed a speeded response task in which participants had to judge mixed-race targets under time pressure.

Ranganath, Smith, and Nosek (2008) demonstrated that automatic attitudes could be assessed by means of speeded self-reports, and not just by use of implicit measures. In their study, confirmatory factor analyses showed that a two-factor model with one latent dimension comprised of both speeded self-report and implicit measures, and another dimension comprised of controlled self-report measures, fit the data better than two latent dimensions covering implicit measures on the one hand, and explicit measures on the other. Additionally, we tested the effect of target gender in Experiment 2. Both evolutionary and socialization theories in intergroup relations view males as the primary targets of intergroup attitudes and behavior (Eagly \& Kite, 1987; Navarrete, McDonald, Molina, \& Sidanius, 2010; Sidanius \& Pratto, 1999). Thus, we examine whether biracial male targets are also the primary targets of hypodescent.

\section{Participants}

Nineteen participants were recruited through the Department of Psychology Study Pool at a university in New England. The study pool draws upon students and members of the surrounding community. The mean age was 25.21 years $(S D=11.19)$ and 14 were female. Only participants who self-identified as White were recruited ${ }^{2}$, and participants received either $\$ 5$ or course credit in return for participation.

\section{Materials and Procedure}

Computerized family tree task. Our primary measure involved a computer task we created using DirectRT software to present and gather responses to family trees. The family trees we 
presented depicted 4 grandparents and a target grandchild. The factors that varied in the trees were the number of minority grandparents ( 0 to 4$)$ and the gender of the target grandchild. Thus, a tree could have 4 White, 4 Asian, or 4 Black grandparents, or a mix of Asian and White or Black and White grandparents. Asian and Black grandparents were never mixed (see Figure 1).

For each combination (e.g., 1 Asian and 3 White grandparents with granddaughter), participants were asked 3 questions: “Is the granddaughter Asian?”, “Is the granddaughter mixed?”, or “Is the granddaughter White?”. In the case where a male target was presented, the questions were substituted with “grandson” and for Black-White targets, “Black” replaced “Asian” in the question. In the case where there were 4 White grandparents, participants were asked whether the target was White, mixed, Asian, or Black.

For each question, participants were instructed to respond by pressing a key labeled “yes” or a key labeled "no.” Since we wanted the task to require relatively reflexive rather than deliberative responses, each tree was presented for a maximum of 2500 milliseconds. If a participant did not respond within this timeframe, a message appeared that read, "Please try to respond faster!” However, no response was required, and a different family tree was subsequently presented.

Verbal labels were used to indicate the race of the grandparents, and a small symbol depicted a target grandchild's gender. Gender was also indicated by color-coding the symbols and the words granddaughter or grandson pink and blue, respectively. In cases where there were 1,2 , or 3 minority grandparents, the position of the minority grandparent(s) in the tree were randomly assigned. For example, with 1 Black grandparent, that grandparent could occupy the first, second, third, or fourth position from left to right. 
Taking the above factors into consideration, 56 combinations were possible, and each combination was presented 10 times. Combinations were presented in random order. Thus, there were 560 trials, with a 10 second break after each block of 140 trials. For example, in the case of 3 Asian grandparents and a granddaughter, participants were asked if the target was Asian, mixed, or White 10 times each. This formed the basis of our primary dependent variable, which was how many times out of 10 a participant would respond that a particular target was minority (Asian or Black) or White. For example, if a participant was presented with 2 Black and 2 White grandparents and a target grandson, they could respond that the grandson was White from 1 to 10 times.

Analyses were based primarily on planned contrasts looking at how many times out of 10 a participant responded “yes” to a given racial label for a target as a function of grandparent race and target gender. Because we were primarily interested in the relative association of mixed race targets with their minority or White parent groups, we focus on the use of the Asian, Black, and White labels.

\section{Results and Discussion}

Before conducting our primary analyses of interest, we first assessed whether participants were able to respond to our speeded response task in a logical, non-random fashion. Specifically, we collapsed responses to Asian-White and Black-White male targets and compared the percentage of trials in which participants responded "yes" to the question of whether the target grandson is minority (Asian or Black) when there was 1 minority grandparent versus 0 minority grandparents.

Consistent with expectations, participants were more likely to respond “yes” to this question when 1 grandparent was minority ( $m=34.5 \%$ of trials, $S D=35.5 \%$ ) than when 0 
grandparents were minority $(m=6.8 \%$ of trials, $S D=10.2 \%, t(18)=3.23, p<.01, r=.61)$. Since we were interested in the number of times out of ten that a participant responded to a particular trial-type with a particular response, we express means and standard deviations in percentages throughout Experiments 2A and 2B.

Having established that participants are able to respond to our program in a non-random fashion, we turned to analyses of responses when half of the grandparents presented were minority and half were White. Inspection of the mean proportions in acceptance of minority and White labels suggested that there was a hypodescent effect (see Table 1). Indeed, a 2 (White label vs. minority label) x 2 (half-Asian target vs. half-Black target) x 2 (male target v. female target) repeated measures ANOVA found a main effect for racial label, revealing greater acceptance of the minority labels than the White label for half-minority targets $(F(1,18)=8.24$, $p=.01, r=.56$; see Figure 2). ${ }^{3}$

We also conducted a 2 (White label vs. minority label) x 2 (quarter-Asian target vs. quarter-Black target) x 2 (male target v. female target) repeated measures ANOVA examining responses to quarter-minority targets (see Table 1 for means and $S D$ ). This revealed a marginally significant target race by racial label interaction $(F(1,18)=2.93, p=.10, r=.37)$, suggesting that there is a greater difference in the use of the minority label relative to the White label for Black-White targets.

A simple effects analysis shows that while quarter-Black targets tend to have a minority label accepted more than a White label, this is not significant $(F(1,18)=.49, p=.50, r=.16)$. The opposite tendency for quarter-Asian biracials to be rated as more White than minority was also not significant $(F(1,18)=.20, p=.67, r=.10)$. However, another planned contrast showed that the minority label was used more for quarter-Black males than for quarter-Asian males $(F(1$, 
18) $=6.33, p<.05, r=.51$; see Figure 3 ). The minority label was not used significantly more often for quarter-Black female targets compared with quarter-Asian female targets $(F(1,18)=$ $.71, p=.41, r=.19)$.

There was also no difference in the use of the White label between quarter-Asian and Black male targets $(F(1,18)=.53, p=.48, r=.17)$ or between quarter-Asian and Black female targets $(F(1,18)=1.38, p=.26, r=.27)$. Finally, there was also a marginally significant main effect for gender $(F(1,18)=3.95, p=.06, r=.42)$ suggesting that male targets elicited more affirmative responses in general, regardless of the target race or given racial label. While this latter finding is not directly relevant to our hypotheses, it is consistent with the view that men are the primary exemplars of ethnic and national groups (Eagly \& Kite, 1987).

The results of this speeded response task revealed again that hypodescent is likely applied to both Asian-White and Black-White targets, but that it might apply more strongly to BlackWhite targets. Moreover, compared to Experiment 1, the effect sizes were much larger. ${ }^{4}$ We found a greater magnitude of hypodescent for both half-Asian and half-Black targets. Furthermore, with respect to quarter-Asian and Black male targets, we found an unambiguous, strong difference consistent with the order of the American racial hierarchy, such that the minority label was deemed more appropriate for biracial Black targets than for biracial Asian targets. Finally, there was some hint of a gender effect, such that the racial hierarchy in hypodescent applied most clearly to quarter-minority males, with quarter-Black males being seen as more minority than quarter-Asian males.

Experiment 2B: A Replication 
We designed Experiment 2B to replicate the findings in Experiment 2A. Specifically, we used a similar speeded-response task to test for (a) hypodescent and (b) a racial hierarchy in hypodescent. We also pursued the gender effect observed in the previous experiment.

\section{Participants}

Twenty-four participants were recruited from the Department of Psychology Study Pool at a university in New England, and participated in exchange for course credit or \$5. Only White participants were recruited $^{5}$, and 11 were male and 13 were female. The mean age was 28.04 years $(S D=13.69)$.

\section{Materials and Procedure}

The computerized family tree task used for this study had the same format and randomization pattern as Experiment 2A. Instead of using verbal labels to depict the grandparents' race in this study, we used black and white (i.e., grayscale) pictures. For each race (Asian, Black, and White), we had two male and two female pictures. Thus, if one grandparent was Asian, for example, any one of the four Asian pictures could represent the grandparent. The other change was in the size of the symbol representing gender. We made the symbols bigger in the present study to make gender more salient, and thus further explore any possible gender effects.

\section{Results and Discussion}

Our first analysis concerned responses when half of the grandparents presented were minority and half were White (see Table 1). A 2 (White label vs. minority label) x 2 (half-Asian target vs. half-Black target) x 2 (male target v. female target) repeated measures ANOVA found a main effect for racial label, revealing greater acceptance of the minority labels than the White label for half-minority targets $(F(1,23)=9.56, p<.01, r=.54$; see Figure 4). A racial label $\mathrm{x}$ 
target race interaction $(F(1,23)=9.54, p<.01, r=.54)$ and racial label by target sex interaction also emerged $(F(1,23)=4.92, p<.05, r=.42)$. The simple effects analysis following up on the racial label x target race interaction shows that while the hypodescent effect is significant for Black-White targets $(F(1,23)=14.59, p<.01, r=.54)$, it is less strong and marginally significant for Asian-White targets (i.e., $F(1,23)=3.56, p=.07, r=.37$ ). The contrasts for the racial label x target sex interaction suggest that hypodescent was pronounced for male targets $(F(1,23)=12.98, p<.01, r=.60)$, and present but expectedly weaker for female targets $(F(1$, 23) $=5.49, p<.05, r=.44)$. To further decipher these interactions, and due to our apriori interest in gender, we looked at the simple effects of racial label within each target race and gender group. This revealed that the hypodescent was strongest for Black males $(F(1,23)=$ 14.99, $p=.001, r=.63)$, followed by Black females $(F(1,23)=9.67, p<.01, r=.54)$, followed by Asian males $(F(1,23)=6.32, p<.01, r=.46)$. The effect was weakest among Asian females $(F(1,23)=1.19, p=.29, r=.22) . \quad$ The finding of a significant hypodescent effect for BlackWhite females, but not for Asian-White females, highlights the strength of hypodescent in the Black-White condition.

We also conducted a 2 (White label vs. minority label) x 2 (quarter-Asian target vs. quarter-Black target) x 2 (male target v. female target) repeated measures ANOVA examining responses to quarter-minority targets (see Table 1). There was a marginally significant effect of race label such that these targets, who were three-quarters-White had the White label accepted marginally more than the minority label $(F(1,23)=3.01, p=.10, r=.34)$. However, this was qualified by a target race by racial label interaction $(F(1,23)=10.14, p<.01, r=.55$; see Figure 5), suggesting a pattern of hypodescent consistent with the extant racial hierarchy. A simple effects analysis showed that among quarter-Asian targets, the White label was accepted more 
often than the minority label $(F(1,23)=7.63, p=.01, r=.50)$. However, among quarter-Black targets, there was no difference in how often the 2 labels were accepted $(F(1,23)=.30, p=.59, r$ $=.11)$.

The results of this study give assurance of the reliability of this empirical discovery. Again, when targets were half-White and half-minority, the Asian and Black labels were accepted more often than the White label, regardless of whether the target was half-Asian or half-Black. However, a racial hierarchy in hypodescent (i.e., a pattern of hypodescent consistent with the extant racial hierarchy) and gender effect also emerged, such that this did not apply as much to half-Asian targets in general, and to half-Asian females in particular. Thus, while a form of hypodescent seems to apply to both mixed-Asians and mixed-Blacks, we again find this to be consistent with the extant racial hierarchy, with mixed-Blacks being more readily identified as minority.

This pattern of differential application of hypodescent was further evidenced when there was only one minority grandparent, albeit in a different form than was found in Experiment 2A. In the present study, participants were more likely to accept the White label than the Asian label for quarter-Asian targets, but equally likely to use the Black and White labels for quarter-Black targets. Taken together, the evidence from this study would suggest that hypodescent applies to targets of Asian and White descent to a certain extent, but not as severely as toward part-Black targets. Interestingly, a gender effect emerged again, indicating that while hypodescent may be applied to female targets, it might be applied more strongly to male targets.

Experiment 3A: Evidence of Hypodescent in Visual Face Perception Thus far, our understanding of whether there is hypodescent or a racial hierarchy in hypodescent has been based on peoples’ judgments of targets known to have particular parents 
from differing racial categories. We now move to testing whether the direct visual perception of such targets may also reveal hypodescent. In other words, experiments 3A and 3B examined whether hypodescent also operates by distorting how the target is seen visually.

In addition, Experiments 1, 2A, and 2B consistently revealed results consistent with the extant racial hierarchy in hypodescent. However, it was not clear whether this pattern was a function of perceiving Asian-White targets as more White, or as less minority than Black-White targets. The next two experiments enabled us to further assess the source of the racial hierarchy in hypodescent, perhaps pointing to an additional mechanism by which it emerges.

Finally, Experiments 3A and 3B enabled us to approximate thresholds for being perceived as White or minority. Previously, we gave people racial background information indicating that a target was a quarter minority, or half minority, and asked them to judge whether a target was White or minority based on this information. In these last studies, we have participants judge targets along a continuum using a face morphing task, and thus are better able to examine whether there are different thresholds for being perceived as White or minority, and whether that is a function of target race. Thus, Experiments 3A and 3B will look for convergent evidence of hypodescent and a racial hierarchy in hypodescent using a face morphing task that will enable us to see: 1) if the visual perception of targets’ facial features matter, 2) if racial hierarchy is due to differentially seeing targets as White or differentially seeing them as minority, and 3) if different thresholds apply to seeing Asian-White and Black-White biracials as White or minority.

\section{Participants}

50 participants were recruited from the Department of Psychology Study Pool at a university in New England and participated online. Participants were given course credit for 
their participation. 31 participants were Caucasian/White, 8 African American/Black, 5 Latino/Hispanic, 3 Asian/Asian-American/Pacific Islander, 1 Native American, 1 Biracial/Mixed race, and 1 “other”. Thirty-three were female, 17 male, and the average age was 28.52 (SD = 12.32), since the study pool included both traditional college courses with a younger enrollment and an online course the University was offering for non-degree students.

\section{Materials and Procedure}

Three composite male faces (1 Asian, 1 Black, and 1 White) were created using a morphing program (Morph 2.0.1; Gryphon Software Corporation, 1992-1994). These composite faces were each composed of 4 adult male faces with neutral expressions. The Black and White faces have been used in previous race perception studies (Levin, 1996; Levin \& Banaji, 2006). Asian and Black faces were pretested so that they could be matched on distinctiveness, darkness, and contrast. Distinctiveness was assessed by asking a group of participants in a pilot study, "How distinctive is this face? That is, how well would this person stand out in a crowd?" These participants responded on a seven point scale, with $1=$ "Not well at all" and $7=$ "Very well”. The mean distinctiveness for the four Asian faces used to form the Asian composite was 4.35 $(S D=.82)$, while the mean rating for the four Black faces was $4.42(S D=.66)$. All pictures were 360 x 504 pixels. The same White composite picture was used to create both the Asian-White and Black-White morphs.

Participants morphed pictures in 5\% increments from Asian to White (AW), Black to White (BW), White to Asian (WA), or White to Black (WB). Participants morphed these pictures in one of four orders: 1) AW, BW, WA, WB, 2) BW, AW, WB, WA, 3) WA, WB, AW, BW, and 4) WB, WA, BW, AW. Participants completed the sequence they were randomly assigned to twice, for a total of eight morphing trials. For each trial, they were told what race the 
starting picture in a morph trial represented. Participants were further instructed to press continue until they believed the person represented a member of the other race the biracial morph was created from. Thus, they were told, "The person pictured on the next page is of Asian descent. By pressing the "continue" button at the bottom right hand corner, the person will begin to look part White. Continue pressing the "continue" button until you consider the person to be White. AS SOON AS YOU CONSIDER THE PERSON TO BE WHITE, select yes, and then press the "continue" button again. The face WILL NOT change in equal increments, so you should only rely on what you see.” The last part of this instruction was given to prevent participants from simply counting the number of times they pressed continue across trials to make their responses consistent. In fact, the morphs really did change in equal 5\% increments. The beginning and end group in this instruction could also be Black or White, depending on the morph trial.

\section{Results and Discussion}

We first assessed the presence of a differential threshold for being perceived as minority versus White - in particular, whether perception as minority required a lower threshold than perception as White. To do so, we collapsed responses to AW and BW morphs and responses to WA and WB morphs. A two-way morph direction (White to minority versus minority to White) by target race (Asian-White or Black-White) repeated measures ANOVA revealed a main effect of morph direction, indicating that a target had to be a lower percentage minority to be perceived as minority $(46.67 \%)$ than they had to be White $(65.20 \%)$ to be perceived as White $(F(1,44)=$ 124.41, $p<.001, r=.86)^{67}$.

We also found a main effect for Black-White versus Asian-White targets $(F(1,44)=$ 11.22, $p<.01, r=.45$ ), which was qualified by an interaction with the direction in which 
participants were morphing the targets (i.e., minority to White versus White to minority; $F(1,44)$ $=4.06, p=.05, r=.29$; see Figure 6). These main and interaction effects were consistent with the extant racial hierarchy such that targets had to be $67.83 \%$ White to be perceived as White if they started as Black, but only 62.56\% White if they started out as Asian. This contrast was significant, with $F(1,44)=13.08, \mathrm{p}<.01, r=.48$. Morphing from White to minority, AsianWhite and Black-White targets had to be approximately the same proportion minority to be perceived as minority (46.28\% Asian vs. 47.06\% Black; $F(1,44)=.30, p=.59, r=.08)$.

Experiment 3A demonstrated more directly than previously the presence of a lower threshold for being perceived as minority than there is for being perceived as White, a finding that is consistent with a rule of hypodescent. In addition, we again found hypodescent results consistent with the extant racial hierarchy, such that the barrier for being perceived as White was higher for Black-White targets than it was for Asian-White targets. Interestingly, while the threshold for being perceived as White was higher for mixed-Black targets, the threshold for being perceived as minority was equal for both mixed-race targets, suggesting that Asian-White biracials are equally susceptible to being viewed as minority. That is, when a target was morphed from White to minority, Asian-White targets were seen as minority at the same point that Black-White targets were seen as minority.

Importantly, these findings suggest that hypodescent occurs even when participants see the biracial targets directly. If the perception that a biracial target is a member of a particular group depended exclusively on facial features, then participants would have judged that targets change from minority to White and White to minority at the same point. Instead, the threshold for being perceived as White was higher. The effect of the morph direction (i.e., morphing from minority to White versus White to minority) also suggests that these effects cannot simply be 
attributed to the stimuli we used. If judgments depended solely on the nature of these stimuli, then we would expect the Asian-White/Black-White difference to emerge in both directions.

\section{Experiment 3B: A Replication and Extension}

In Experiment 3A, we began to identify what the threshold is for perceiving Asian-White and Black-White biracials to be White and minority, and found evidence that biracial perception is guided by something other than visual cues. Our goal in Study 3B was to directly replicate these findings using smaller $1 \%$ increments in the morphing task, because smaller increments may be even more sensitive in detecting differences in perceiving different biracial targets. We also used a completely randomized design in this experiment. In addition, we added a speeded racial categorization task in which participants were presented with mixed-race targets of various proportions Asian-White or Black-White, and asked to determine whether the target was minority or White. This gave us an additional measure to further test hypodescent and its consistency with the present racial hierarchy.

\section{Participants}

Eighty-six participants were recruited from the Department of Psychology Study Pool at a university in New England, and given course credit or \$5.00 in return for participation. Fortysix were Caucasian/White, 16 were Asian/Asian American/Pacific Islander, 8 were African American/Black, 5 were Latino/Hispanic, 8 were Biracial/mixed race, and 3 were unknown. Fifty were female, and the average age was $25.79(S D=11.03)$.

\section{Materials and Procedure}

Stimuli for the morph task were the same as in Experiment 3A. However, in this study, participants morphed pictures in 1\% increments. Again, participants responded to each type of morph (AW, BW, WA, or WB) twice, for a total of 8 morphing trials. The order of these 8 trials 
was completely randomized. Participants saw this instruction before each trial: “On the next page, you will see an Asian person. Each time you press the spacebar, the person will look more White. Continue pressing the spacebar until you consider the person to be White, but do not keep the spacebar pressed down. AS SOON AS YOU CONSIDER THE PERSON TO BE WHITE, press "Y". The face WILL NOT change in equal increments, so you should only rely on what you see. Respond quickly - Each screen will go away after 2 seconds and move on to the next picture. Press the spacebar when you are ready to proceed.”

After the morphing task, participants completed a categorization task in which they were presented with Asian-White and Black-White targets, and asked to decide whether the targets were minority or White by pressing “M” for minority and "W" for White. Specifically, participants read the following instructions: “On the following pages, you will see pictures of faces that are part-White and part-Asian or part-White and part-Black. For each face, press "W" if you would consider the person to be White, and press "M" if you would consider the person to be minority (i.e., Asian or Black). Respond quickly - Each screen will go away after 2 seconds and move on to the next picture. Press the spacebar when you are ready to proceed.”

Participants saw both Asian-White and Black-White morphs in 5 percent increments (e.g., 45\% Black-White, or 70\% Asian-White; this differs from the morphing task, which used 1\% increments). Thus, there were 38 biracial targets (19 Asian-White and 19 Black-White) and three monoracial targets (1 Asian, 1 Black, and 1 White). Each was presented twice in randomized order for a total of 84 trials (monoracial White target was presented four times). This task was speeded as well, in that participants were given 2 seconds to respond to each picture. We did not reveal the proportion of minority descent for any target, so participants had to rely solely on their perception of each picture. 


\section{Results and Discussion}

As in Experiment 3A, we first looked for evidence of hypodescent in a main effect of morph direction. A two-way morph direction (White to minority versus minority to White) by target race (Asian-White or Black-White) repeated measures ANOVA revealed a main effect of morph direction, indicating that a target had to be a lower percentage minority to be perceived as minority $(45.82 \%)$ than they had to be White $(59.57 \%)$ to be perceived as White $(F(1,80)=$ 83.43, $p<.001, r=.71)^{89}$.

We also found a main effect for Black-White versus Asian-White targets $(F(1,80)=$ 4.48, $p<.05, r=.23$ ), which was qualified by an interaction with the direction in which participants were morphing the targets (i.e., minority to White versus White to minority; $F(1,80)$ $=9.45, p<.01, r=.33$; see Figure 7). These main and interaction effects suggested a racial hierarchy in hypodescent, such that targets had to be $62.13 \%$ White to be perceived as white if they started as Black, but only 56.50\% White if they started out as Asian. This contrast was significant, with $F(1,80)=13.96, p<.001, r=.39$. Morphing from White to minority, AsianWhite and Black-White targets had to be approximately the same proportion minority to be perceived as minority (46.78\% Asian vs. 44.86\% Black; $F(1,80)=1.59, p=.21, r=.14)$.

We also looked for hypodescent and racial hierarchy effects in the categorization data. Specifically, we first looked to see how 50\% Asian-White and Black-White targets were categorized (as minority or White). To do this, we assigned participants a score of 1 for each time they categorized a particular target as White. Since they categorized each target twice, the maximum score would be 2 if they categorized the same target as White twice, and the midpoint is 1. A one-sample t-test from this midpoint revealed that Asian-White targets were significantly more likely to be categorized as minority than as White $(t(79)=-15.62, p<.001, r=.87)$. The 
same test also revealed that Black-White targets were significantly more likely to be categorized as minority $(t(79)=-17.26, p<.001, r=.89)$.

With respect to a racial hierarchy in hypodescent, we found that among $40 \%$ and $65 \%$ minority targets (the only other points at which the Black-White/Asian-White difference was significant), Black-White targets were significantly more likely than Asian-White targets to be categorized as minority $(t(80)=2.39, p<.05, r=.26$ and $t(69)=2.56, p<.05, r=.29$ respectively). For the biracial targets implicated in the effects just described (i.e., Asian-White and Black-White targets who were 40\%, 50\%, and 65\% minority), White and non-White respondents responded in a similar manner, with 1 exception. In the case of a $50 \%$ Black-White target, White respondents rated the target as relatively more White than non-White respondents $(t(78)=-2.78, p<.01, r=.30)$.

We also conducted a binomial test to see if among all paired biracial targets (e.g., 50\% Black-White vs. 50\% Asian-White), there was a significant tendency to rate Black-White targets as relatively minority compared to Asian-White targets. This test showed that among the 15 biracial pairs (out of 19) for which there was a difference, Black-White biracials were rated as relatively more minority in every case $(p=.00)$.

Replicating our results from Experiment 3A, we again found in a face morphing task that participants had a lower threshold for perceiving a mixed-race target as minority than for perceiving a target as White, a finding consistent with hypodescent. We also obtained a hypodescent effect by looking at the categorization of 50\% minority-White targets. Consistent with findings from Experiments 1, 2A, 2B, and 3A, 50\% targets were categorized as more minority than White, regardless of whether the target was Asian-White or Black-White. Furthermore, we replicated the racial hierarchy in hypodescent we found in the first four 
samples, showing that the threshold for being perceived as White is lower for Asian-White targets than for Black-White targets in the morphing task.

Finally, Black-White targets were relatively more likely to be categorized as minority in the categorization task. Importantly, Experiments 3A and 3B provided convergent evidence using tasks that had participants visually perceive mixed-race targets directly.

General Discussion

Across 3 experiments employing 5 independent samples, we found consistently that hypodescent applies to both Asian-White and Black-White biracial targets, and that the magnitude of the effect is greater for Black-White targets, reflecting the prevailing racial hierarchy. In Experiment 1, we saw that both half Asian and half Black targets were categorized as relatively more minority than White. Experiment 1 also provided preliminary evidence that the effect might be stronger for part-Black targets. Experiments 2A and 2B presented participants with a speeded response task to assess reflexive rather than deliberative evaluations of biracials, and found that participants accepted a minority label for Asian-White and BlackWhite targets with 2 White and 2 minority grandparents more than they accepted a White label. This again reflects a pattern of hypodescent. We also found more compelling evidence for an effect consistent with the current racial hierarchy, whereby participants found a minority label more descriptive of quarter-Black targets than of quarter-Asian targets, and a White label more descriptive of quarter-Asian targets. In addition, gender proved to be a factor as well, such that the hypodescent effect was stronger for male targets than for female targets.

Furthermore, Experiments 3A and 3B converged on the pattern observed in Experiments 1, 2A, and 2B, by identifying thresholds for being perceived as White or minority for both Asian-White and Black-White targets and by use of a speeded racial categorization task. 
Specifically, we found that the threshold for being perceived as minority was lower than the threshold for being perceived as White, a finding consistent with a pattern of hypodescent. Furthermore, the threshold for being perceived as White was lower for Asian-White targets than for Black-White targets, which is consistent with the current racial hierarchy. Finally, the speeded racial categorization task revealed that both Asian-White and Black-White biracials are more likely to be categorized as minority than as White, and Black-White biracials are categorized as minority more than Asian-White biracials. These final studies required participants to directly perceive and judge biracial targets, rather than judge an unseen target given racial background information.

Importantly, the range of methods employed, and modes of responding that were explored, and the examination of hypodescent outside of the Black-White case allowed us to discover how pervasive the rule of hypodescent may be. The explicit measures we used in Experiment 1 revealed that a rule of hypodescent governs conscious beliefs regarding biracials, and went beyond previous research in establishing that people regard biracials as not just belonging to more than one racial group, but belonging more to their minority parent group than dominant parent group. A parallel can be seen in Experiments 2A and 2B, where we show that hypodescent operates at a more automatic level as well. Experiments 3A and 3B involved the direct visual perception of biracial targets and asked participants to determine for themselves at what point a target had changed from one race to another (face morphing task), or should be considered minority or White (categorization task). In these studies, we did not specify the proportion of minority descent for each target. This allowed us to assess a different version of hypodescent - the ability of the eye to "see" biracials as belonging to the more disadvantaged parent group. The finding of hypodescent in the Asian-White case reveals, for the first time, 
how pervasive the rule of hypodescent is, not only in terms of the varied conditions under which it operates, but also in terms of its application to biracials outside the Black-White context. Together, these studies establish the wide reach of hypodescent in guiding the categorization and perception of biracials.

The finding that a rule of hypodescent guides how Asian-White biracials are perceived counters much of the prevailing wisdom in the social sciences (Alba \& Nee, 2003; Lee \& Bean, 2004; 2007a; 2007b; Sears \& Savalei, 2006; Thornton, 2009). This received wisdom was recently expressed again in a New York Times article on interracial marriage, in which the political scientist Andrew Hacker stated, "Children of white-Asian and white-Hispanic parents will have no problems calling themselves white, if that's their choice (Roberts, 2010).” Scholars assuming that biracial Asian-White individuals will readily assimilate to the American mainstream have taken as evidence the self-identity of biracials. For example, Lee and Bean (2007b) cite US Census data showing that among Asian-White couples choosing a single race for their children, the majority choose White, and provide qualititative data showing that some Asian-White biracials find their race to be inconsequential. One Asian-White biracial man in their study stated, “I don’t think race matters that much.... I don’t really feel it’s going to affect me. I don’t see limits.” Our data reveal that people do use Asian-White biracials’ Asian identity in judging them, and perceive them to be more Asian than White.

For African Americans, the likelihood that intermarriage with Whites implies integration in the American mainstream is even lower. As with Asian-White biracial targets, Black-White biracial targets were consistently seen as more Black than White across all five samples. Many Black-White biracials appear to understand that others view them as Black, and consequently identify as Black (Lee and Bean, 2007b). Our data on social categorization and perception 
complements this self-identity data well, and again gives pause to the assumption that intermarriage (and mixed ancestry) is a good "litmus test of assimilation (Alba and Nee, 2003, p. 90).”

Instead of a rapid shift in the existing racial hierarchy, it would appear that the pattern of hypodescent observed for part-Asian and part-Black targets reflects the structure of the hierarchy. Social dominance theorists (Sidanius \& Pratto, 1999) have long observed that societies tend to be hierarchically arranged, that such arrangements are broadly consensual (i.e., dominants and subordinates agree who is in what position; see, e.g., Kahn, Ho, Sidanius, \& Pratto, 2009), and that a myriad of factors help to maintain existing group-based hierarchies. Throughout these studies, we find that the rule of hypodescent works in a manner consistent with the hierarchical arrangement in the US, and similarly serves to maintain the existing hierarchy.

As we discussed, the finding of gender effects in Experiments 2A and 2B is consistent with the subordinate male target hypothesis within social dominance theory (Navarrete, Olsson, Ho, Mendes, Thomsen, \& Sidanius; Sidanius and Pratto, 1999), and with the finding by social role theorists that males are seen as exemplars of racial groups more so than females (Eagly \& Kite, 1987). This finding provides yet another reason why intermarriage and biracial identification should not be readily accepted as signs of assimilation for Asian Americans. With respect to intermarriage, Asian females are much more likely to intermarry with Whites than Asian males are (Galinsky \& Cuddy, 2009; Lee \& Fernandez, 1998). According to the 2000 United States Census, 75\% of Asian-White marriages (380,475 out of 504,119) were between an Asian female and White male. Thus, even if intermarriage could be taken as a sign of assimilation, it would apply more so to females than to males. Now, we have evidence that hypodescent might also apply more strongly to male targets, making the prospects of biracial 
identification as an index of assimilation for male biracial Asian-White targets dim as well. While target gender was not a factor we were able to consider in Experiments 1 and 3, our findings from Experiment 2A and 2B suggest that gender should be considered in future research on the perception of biracial individuals.

Future studies of hypodescent should also examine potential antecedents of hypodescent. One possible proximate explanation is racism. For example, Blascovich, Wyer, Swart, \& Kibler (1997) showed that racism plays a role in the categorization of racially ambiguous individuals, with those high in racism more likely to take longer to categorize such individuals. Castano, Yzerbyt, Bourguignon, \& Seron (2002) found a similar effect - they discovered that a strong ingroup identity leads to more time spent categorizing racially ambiguous faces as ingroup versus outgroup members, and led to fewer categorizations of targets into the ingroup. Furthermore, high identifiers took longer to accept a target as a member of the ingroup than to reject a target as a member of the outgroup. Castano et al. theorize that the selective inclusion of targets in the ingroup (i.e., "ingroup overexclusion”) serves to protect the integrity of the group. For Whites, this could also explain why biracial targets in our face morphing study were more readily perceived as minority than as White.

Fear of contagion, a more distal explanation, may play a role as well. Rozin \& Royzman (2001) argue that contagion fear may be the root of negativity dominance, or the dominance of negative entities in evaluating objects composed of a negative and positive entity. Thus, social perceivers may believe that the negative attributes of stereotyped minority groups can "spoil” the positive attributes of the dominant group.

For racial minorities categorizing racially ambiguous targets, one factor that might contribute to hypodescent is the desire to preserve an ethnic minority culture. In addition, some 
minorities may want biracials to identify as minority as a signal of racial solidarity and for the purposes of political mobilization (e.g., Hickman, 1997). Interestingly, we found little difference in the use of hypodescent among White and non-White participants in these studies. ${ }^{10}$

Nevertheless, it is important to consider that different motivations might underlie the use of hypodescent among dominant and minority respondents, an issue that future studies can address.

More research is also needed on the consequences of perceiving mixed-race targets as minority. While these studies show that people more readily perceive mixed-race targets as minority than as White, we do not know whether stereotypes associated with monoracial minority group members are also applied to mixed-race targets with equal strength. It is possible that the valence of stereotypes concerning mixed race targets may be more negative than stereotypes about monoracials (Sanchez \& Bonam, 2009) or somewhere in between stereotypes about monoracial minority and White targets. Other research (MacLin \& Malpass, 2001) has demonstrated that once racially ambiguous targets are classified as minority, they are rated in a manner that is consistent with the stereotype of the group they have been categorized as belonging to. Research on "shifting standards" suggests that how biracials are categorized may have serious consequences for the standards they are held to across a variety of stereotyperelevant domains (Biernat, Vescio, \& Manis, 1998).

It is also informative to consider contexts in which the threshold for being considered minority becomes higher rather than lower. For example, the idea of "blood quantum” originated in the Virginia colony in 1705 , when a person who was half Native American was considered inferior to Whites (Forbes, 2000). Later in United States history, multiracials who were quarter-Native American or less (depending on state), were denied privileges granted to people acknowledged to be of European descent. However, in the present context, where 
membership in a Native American tribe confers benefits (e.g., access to natural resources on tribal land), the role of blood quantum has reversed, such that one has to be a quarter Native American or more to be considered Native American (Spruhan, 2007). This requirement is enforced by Native American tribes themselves.

Similarly, in the context of considering applicants for minority-designated internships, or affirmative action, one needs to be more minority to be deemed worthy (Sanchez \& Chavez, 2010). These observations of when thresholds for being viewed as a minority shift reveals how categorization as minority may be tied to access to valued resources - where minority group membership entails disadvantage, the threshold for being considered minority is low (i.e., we observe hypodescent). However, when being minority confers an advantage, then the threshold shifts, and one needs to be more minority to be categorized as such.

Finally, future research should examine why the pattern of Asian-White and BlackWhite hypodescent mirrors the racial hierarchy in the US. While the differential degree of hypodescent used for Asian-White and Black-White biracials clearly and consistently tracks the differential social status of Asian Americans and African Americans in the US, future research should try to establish direct evidence demonstrating that this differential hypodescent is a function of the perceived status differences between the two groups.

\section{Conclusions}

The findings presented here suggest that the American racial hierarchy is still intact. Using questions and methods used for the first time, biracial Black-White and Asian-White individuals were shown to be unequally judged as minority or majority, even when the rational response should have led to an equal assessment. Furthermore, this pattern of hypodescent, while applied to both Asian-White and Black-White target groups, was more strongly applied in the 
Black-White case. As the United States and other nations become more diverse, and rates of intermarriage increase, it will be increasingly important to consider how the current racial hierarchy and its supporting ideologies guide our perceptions of mixed-race individuals. Rather than dictating the structure of our racial hierarchy, miscegenation and perceptions of biracial individuals appear to mirror the prevailing hierarchy. 


\section{References}

Alba, R. D., \& Nee, V. (2003). Remaking the American mainstream: Assimilation and contemporary immigration. Cambridge: Harvard University Press.

Biernat, M., Vescio, T. K., \& Manis, M. (1998). Judging and behaving toward members of stereotyped groups: A shifting standards perspective. In C. Sedikides, J. Schopler, \& C. A. Insko (Eds.), Intergroup cognition and intergroup behavior, pp. 151-175. Hillsdale, NJ: Lawrence Erlbaum Associates.

Blascovich, J., Wyer, N., Swart, L., \& Kibler, J. (1997). Racism and racial categorization. Journal of Personality and Social Psychology, 72(6), 1364-1372.

Brunsma, D. L. (2006). Public categories, private identities: Exploring regional differences in the biracial experience. Social Science Research, 35, 555-576.

Brunsma, D. L., \& Rockquemore, K. A. (2001). The new color complex: Appearances and biracial identity. Identity: An International Journal of Theory and Research, 1(3), 225246.

Castano, E., Yzerbyt, V., Bourguignon, D., \& Seron, E. (2002). Who may enter? The impact of in-group identification on in-group/out-group categorization. Journal of Experimental Social Psychology, 38(3), 315-322.

Cheryan, S., \& Monin, B. (2005). Where are you really from? Asian Americans and identity denial. Journal of Personality and Social Psychology, 89(5), 717-730.

Corneille, O., Huart, J., Becquart, E., \& Brédart, S. (2004). When memory shifts toward more typical category exemplars: Accentuation effects in the recollection of ethnically ambiguous faces. Journal of Personality and Social Psychology, 86(2), 236-250.

Davis, F. J. (1991). Who is black? One nation's definition. University Park: Pennsylvania State 


\section{University Press.}

Devos, T., \& Banaji, M. R. (2005). American = White? Journal of Personality and Social Psychology, 88(3), 447-466.

Eagly, A. H. \& Kite, M. E. (1987). Are stereotypes of nationalities applied to both women and men? Journal of Personality and Social Psychology, 53, 451-462.

Eberhardt, J., Dasgupta, N., \& Banaszynski, T. (2003). Believing is seeing: The effects of racial labels and implicit beliefs on face perception. Personality and Social Psychology Bulletin, 29(3), 360-370.

Etzioni, A (1997, June 8). Let’s not be boxed in by color. Washington Post, p. C03.

Fang, C. Y., Sidanius, J., \& Pratto, F. (1998). Romance Across the Social Status Continuum: Interracial Marriage and the Ideological Asymmetry Effect. Journal of Cross Cultural Psychology, 29, 290-305.

Forbes, J. D. (n.d.). Blood quantum: A relic of racism and termination. In Native Americans. Retrieved from http://nas.ucdavis.edu/Forbes/resources.html.

Galinsky, A., \& Cuddy, A. J. C. (2009). The overlap between racial and gender stereotypes: Towards an understanding of the gender composition of interracial marriages. Manuscript submitted for publication.

Gryphon Software Corporation. (1992-1994). Morph TM 2.0.1 [Computer software]. San Diego, CA: Author.

Harris, D. R., \& Sim, J. J. (2002). Who is multiracial?: Assessing the complexity of lived race. American Sociological Review, 67, 614-627.

Hickman, C. B. (1997). The devil and the one drop rule: Racial categories, African Americans, and the U.S. Census. Michigan Law Review, 95(5), 1161-1265. 
Hirschfeld, L. A. (1995). The inheritability of identity: Children's understanding of the cultural biology of race. Child Development, 66, 1418-1437.

Hugenberg, K., \& Bodenhausen, G. (2004). Ambiguity in Social Categorization: The role of prejudice and facial affect in race categorization. Psychological Science, 15(5), 342345.

Hutchings, P., \& Haddock, G. (2008). Look black in anger: The role of implicit prejudice in the categorization and perceived emotional intensity of racially ambiguous faces. Journal of Experimental Social Psychology, 44(5), 1418-1420.

Kahn, K., Ho, A. K., Sidanius, J., \& Pratto, F. (2009). The space between us and them: Perceptions of status differences. Group Processes and Intergroup Relations, 12(5), 591604.

Lee, J., \& Bean, F. D. (2004). America’s changing color lines: Immigration, race/ethnicity, and multiracial identification. Annual Review of Sociology, 30, 221-42.

Lee, J., \& Bean, F. D. (2007a). Redrawing the color line? City and Community, 6(1), 49-62.

Lee, J., \& Bean, F. D. (2007b). Reinventing the color line: Immigration and America’s new racial/ethnic divide. Social Forces, 86(2), 561-586.

Lee, S. M., \& Fernandez, M. (1998). Trends in Asian American racial/ethnic intermarriage: A comparison of 1980 and 1990 census data. Sociological Perspectives, 41(2), 323-342.

Levin, D.T. (1996). Classifying faces by race: The structure of face categories. Journal of Experimental Psychology: Learning, Memory and Cognition, 22 ,1364-1382.

Levin, D. T. and Banaji, M. R. (2006). Distortions in the perceived lightness of faces: The role of race categories. Journal of Experimental Psychology, 135(4), 501-512. 
MacLin, O., \& Malpass, R. (2001). Racial categorization of faces: The ambiguous race face effect. Psychology, Public Policy, and Law, 7(1), 98-118.

Navarrete, C. D., McDonald, M. M., Molina, L. E., \& Sidanius, J. (2010). Prejudice at the nexus of race and gender: An outgroup male target hypothesis. Journal of Personality and Social Psychology, 98(6), 933-945.

Navarrete, C. D., Olsson, A., Ho, A. K., Mendes, W. B., Thomsen, L., \& Sidanius, J. (2009) Fear extinction to an out-group face: The role of target gender. Psychological Science, 20(2), 155-158.

Pauker, K., Weisbuch, M., Ambady, N., Sommers, S. R., Adams, R. B. Jr., \& Ivcevic, Z. (2009). Not so Black and White: Memory for ambiguous group members. Journal of Personality and Social Psychology, 96, 795-810.

Peery, D., \& Bodenhausen, G. (2008). Black + White = Black: Hypodescent in reflexive categorization of racially ambiguous faces. Psychological Science, 19(10), 973-977.

Ranganath, K. A., Smith, C. T., \& Nosek, B. A. (2008). Separating automatic and controlled components of attitudes from direct and indirect measures. Journal of Experimental Social Psychology, 44, 386-396.

Roberts, S. (2010, June 3). Black women see fewer black men at the altar. The New York Times, p. A12.

Roth, W. D. (2005). The end of the one-drop rule? Labeling of multiracial children in Black intermarriages. Sociological Forum, 20(1), 35-67.

Rozin, P., \& Royzman, E. (2001). Negativity bias, negativity dominance, and contagion. Personality and Social Psychology Review, 5(4), 296-320.

Sanchez, D. T., \& Bonam, C. M. (2009). To disclose or not to disclose: The effect of biracial 
disclosure on perceiver evaluations and target responses. Journal of Social Issues, 65, 129-149.

Sanchez, D. T., \& Chavez, G. (2010). Are you minority enough? Language ability affects targets' and perceivers' assessments of a candidate’s appropriateness for affirmative action. Basic and Applied Social Psychology, 32, 99-107.

Sears, D. O., \& Savalei, V. (2006). The political color line in America: Many “peoples of color” or black exceptionalism? Political Psychology, 27(6), 895-924.

Shih, M., \& Sanchez, D. T. (2009). When race becomes more complex: Towards understanding the landscape of multiracial identity and experiences. Journal of Social Issues, 65,1-11

Sidanius, J., Peña, Y., \& Sawyer, M. (2001). Inclusionary discrimination: Pigmentocracy and patriotism in the Dominican Republic. Political Psychology, 22(4), 827-851.

Sidanius, J., \& Pratto, F. (1999). Social dominance: An intergroup theory of social hierarchy and oppression. New York: Cambridge University Press.

Spruhan, P. (2008). The origins, current status, and future prospects of blood quantum as the definition of membership in the Navajo nation. Tribal Law Journal, 8, 1-17.

Song, M. (2009). Is intermarriage a good indicator of integration? Journal of Ethnic and Migrant Studies, 35(2), 331-348.

Thornton, M. C. (2009). Policing the borderlands: White- and Black-American newspaper perceptions of multiracial heritage and the idea of race, 1996-2006. Journal of Social Issues, 65(1), 105-127.

Waters, M. C. (1991). The role of lineage in identity formation among Black Americans. Qualitative Sociology, 14(1), 57-76.

Willadsen-Jensen, E., \& Ito, T. (2006). Ambiguity and the timecourse of racial perception. Social 
Cognition, 24(5), 580-606.

Willadsen-Jensen, E., \& Ito, T. (2008). A foot in both worlds: Asian Americans' perceptions of Asian, White, and racially ambiguous faces. Group Processes \& Intergroup Relations, 11(2), 182-200. 


\section{Author Note}

This research was supported by a Harvard University Anderson Fund research grant awarded to Arnold K. Ho.

We thank David O. Sears for discussions that inspired part of this research, Jihoon Paul Baek, Amanda Brower, Sarah Gross, Brittany Llewellyn, Dadjie Saintus, Lauren Silver, Elyse Traverse, and Yini Zhang for research assistance, and the Sidanius and Banaji Labs at Harvard University for helpful feedback during all phases of this project.

Correspondence concerning this article should be addressed to Arnold K. Ho, Department of Psychology, Harvard University, 33 Kirkland St., Cambridge, MA 02138. Email: arnoldho@fas.harvard.edu 
Table 1

Means and Standard Deviations for Percentage of Trials in which Minority and White labels were Accepted for Quarter and Half Asian-White and Black-White Male and Female Targets in Experiments $2 A$ and $2 B$

\begin{tabular}{lllll}
\hline Experiment 2A & \multicolumn{2}{l}{ White label } & \multicolumn{2}{l}{ Minority label } \\
\hline Target & Mean & $S D$ & Mean & $S D$ \\
\hline Half Asian-White male & $18.95 \%$ & $30.35 \%$ & $34.74 \%$ & $39.07 \%$ \\
Half Asian-White female & $18.42 \%$ & $29.49 \%$ & $41.05 \%$ & $37.84 \%$ \\
Half Black-White male & $18.42 \%$ & $30.77 \%$ & $43.15 \%$ & $39.02 \%$ \\
Half Black-White female & $17.89 \%$ & $30.65 \%$ & $38.42 \%$ & $41.26 \%$ \\
Quarter Asian-White male & $38.42 \%$ & $37.01 \%$ & $29.47 \%$ & $37.34 \%$ \\
Quarter Asian-White female & $33.15 \%$ & $39.31 \%$ & $32.63 \%$ & $37.98 \%$ \\
Quarter Black-White male & $34.73 \%$ & $38.35 \%$ & $39.47 \%$ & $35.82 \%$ \\
Quarter Black-White female & $27.90 \%$ & $36.14 \%$ & $37.37 \%$ & $41.34 \%$ \\
\hline Experiment 2B & & & & \\
\hline Half Asian-White male & $31.25 \%$ & $32.08 \%$ & $44.58 \%$ & $34.13 \%$ \\
Half Asian-White female & $35.00 \%$ & $32.44 \%$ & $41.67 \%$ & $37.03 \%$ \\
Half Black-White male & $24.16 \%$ & $30.92 \%$ & $49.58 \%$ & $42.17 \%$ \\
Half Black-White female & $27.08 \%$ & $34.07 \%$ & $45.83 \%$ & $37.87 \%$ \\
Quarter Asian-White male & $50.00 \%$ & $30.79 \%$ & $32.92 \%$ & $31.41 \%$ \\
Quarter Asian-White female & $45.00 \%$ & $30.65 \%$ & $31.67 \%$ & $33.19 \%$ \\
Quarter Black-White male & $38.33 \%$ & $33.06 \%$ & $36.67 \%$ & $29.29 \%$ \\
Quarter Black-White female & $38.75 \%$ & $29.53 \%$ & $34.17 \%$ & $32.56 \%$ \\
\hline
\end{tabular}




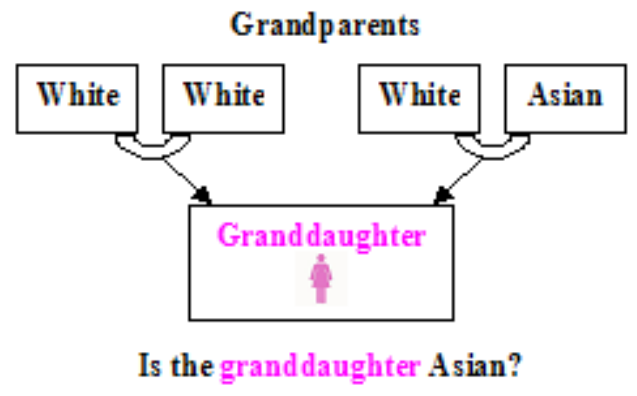

Figure 1. Sample family tree. 


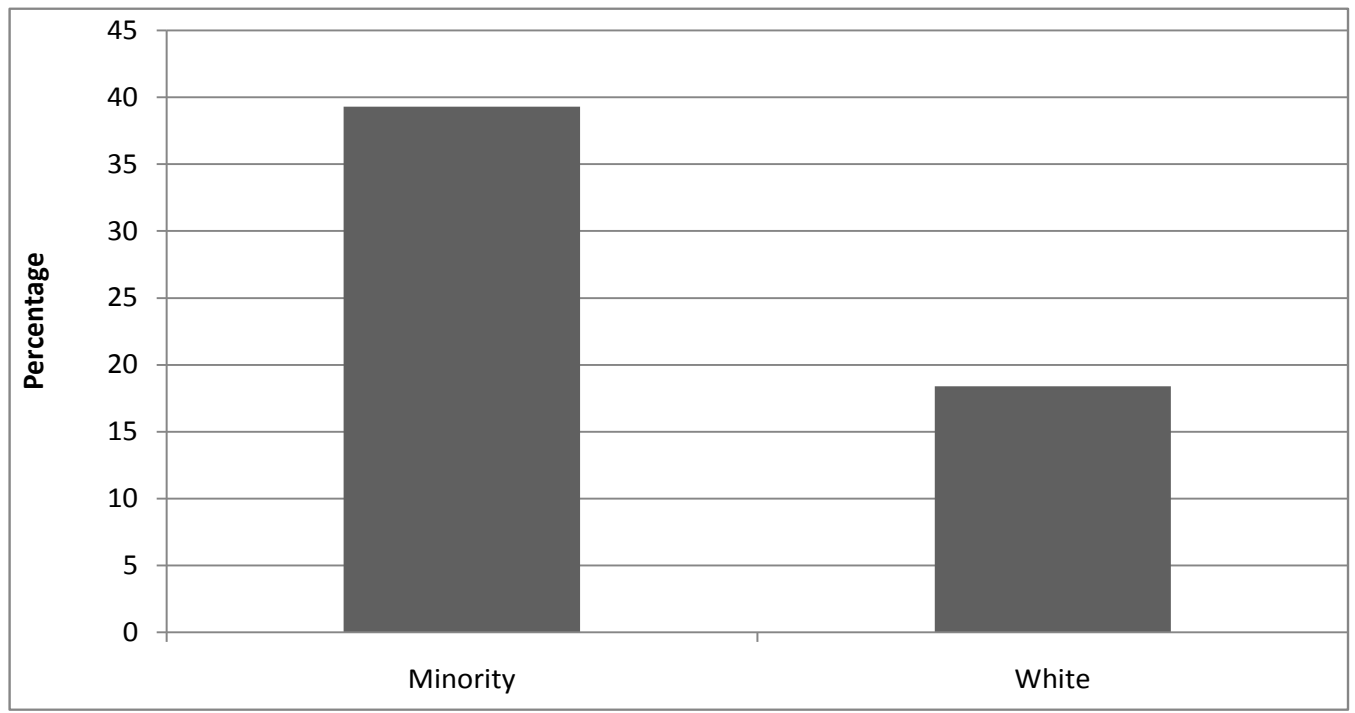

Figure 2. Percentage of trials in which participants responded "yes” to the question of whether the grandchild is minority (Asian or Black) or White when half of the grandparents are minority (Asian or Black). 


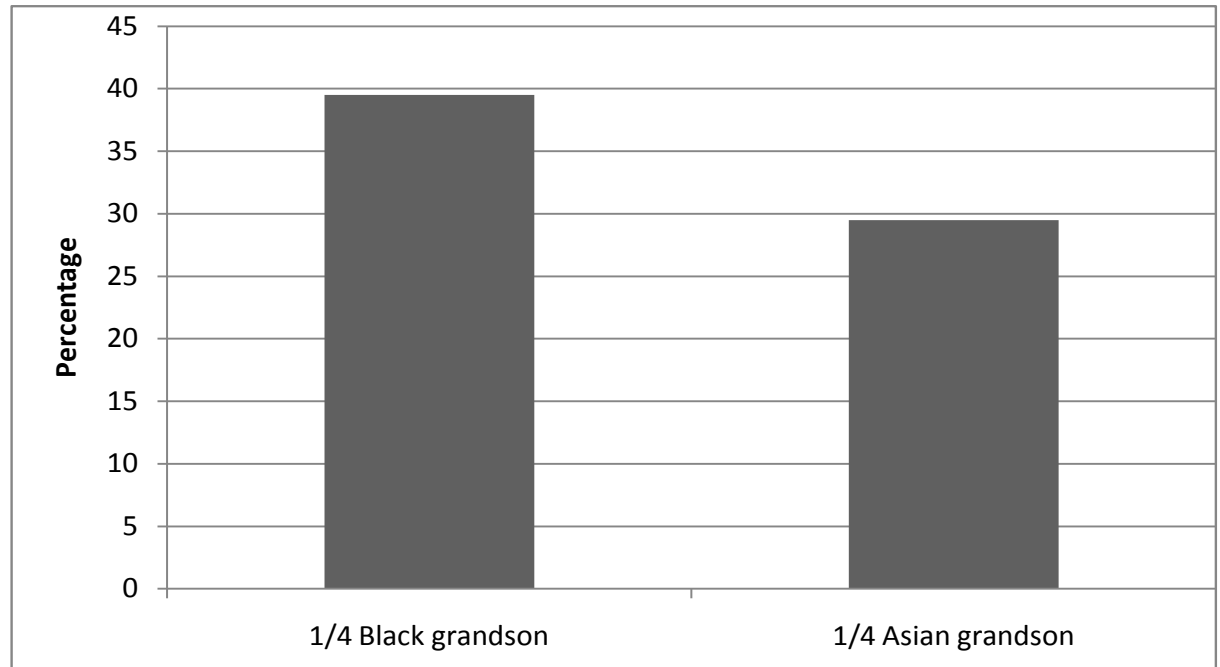

Figure 3. Percentage of trials in which participants responded "yes” to the question of whether the quarter-Black or Asian grandson is minority (Black or Asian). 


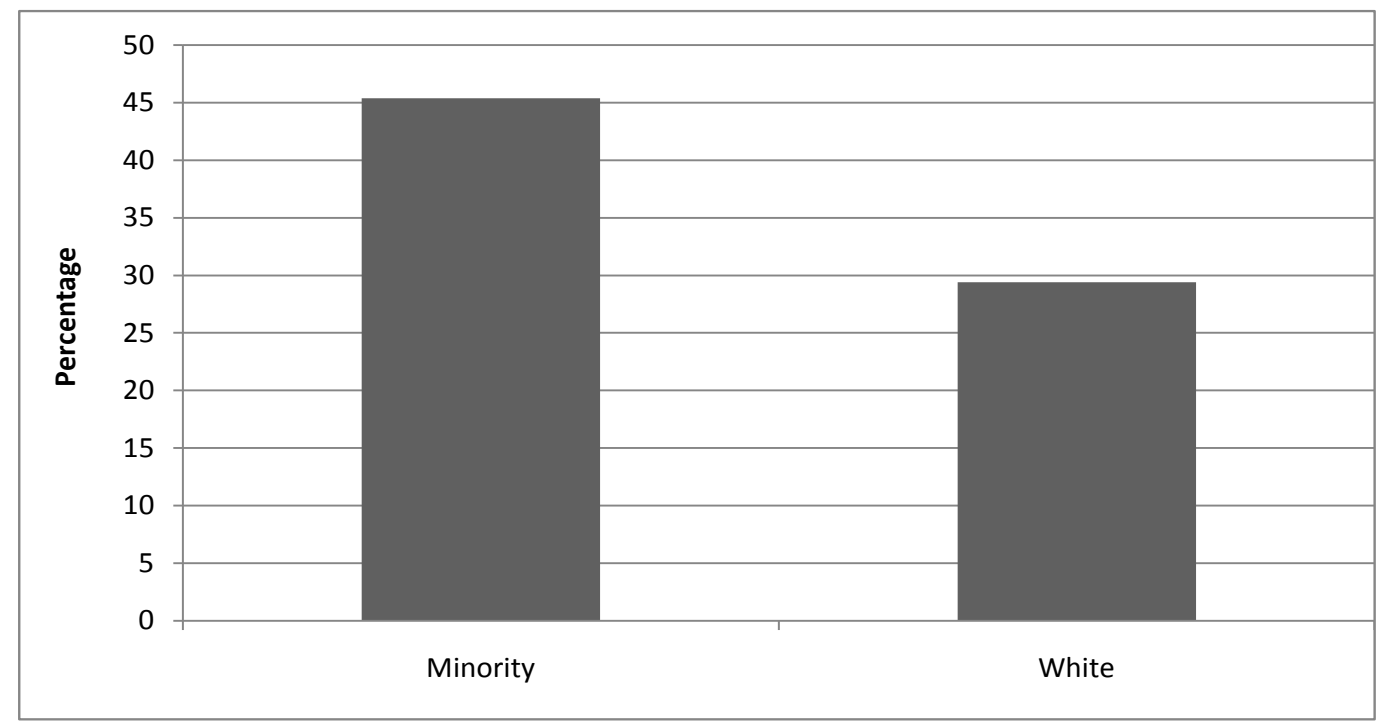

Figure 4. Percentage of trials in which participants responded "yes” to the question of whether the grandchild is minority (Asian or Black) or White when half of the grandparents are minority (Asian or Black). 


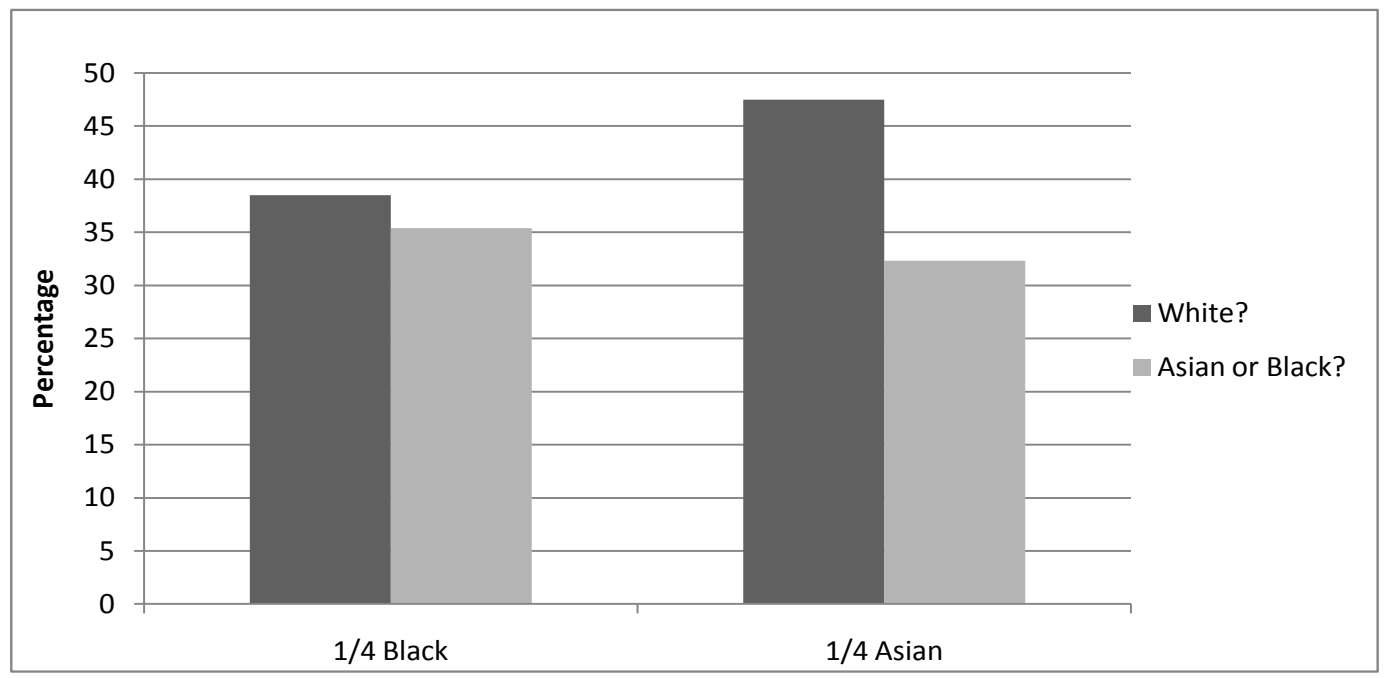

Figure 5. Percentage of trials in which participants responded "yes" to the question of whether the grandchild is White or minority (Asian or Black) for quarter-Black and quarter-Asian targets. 


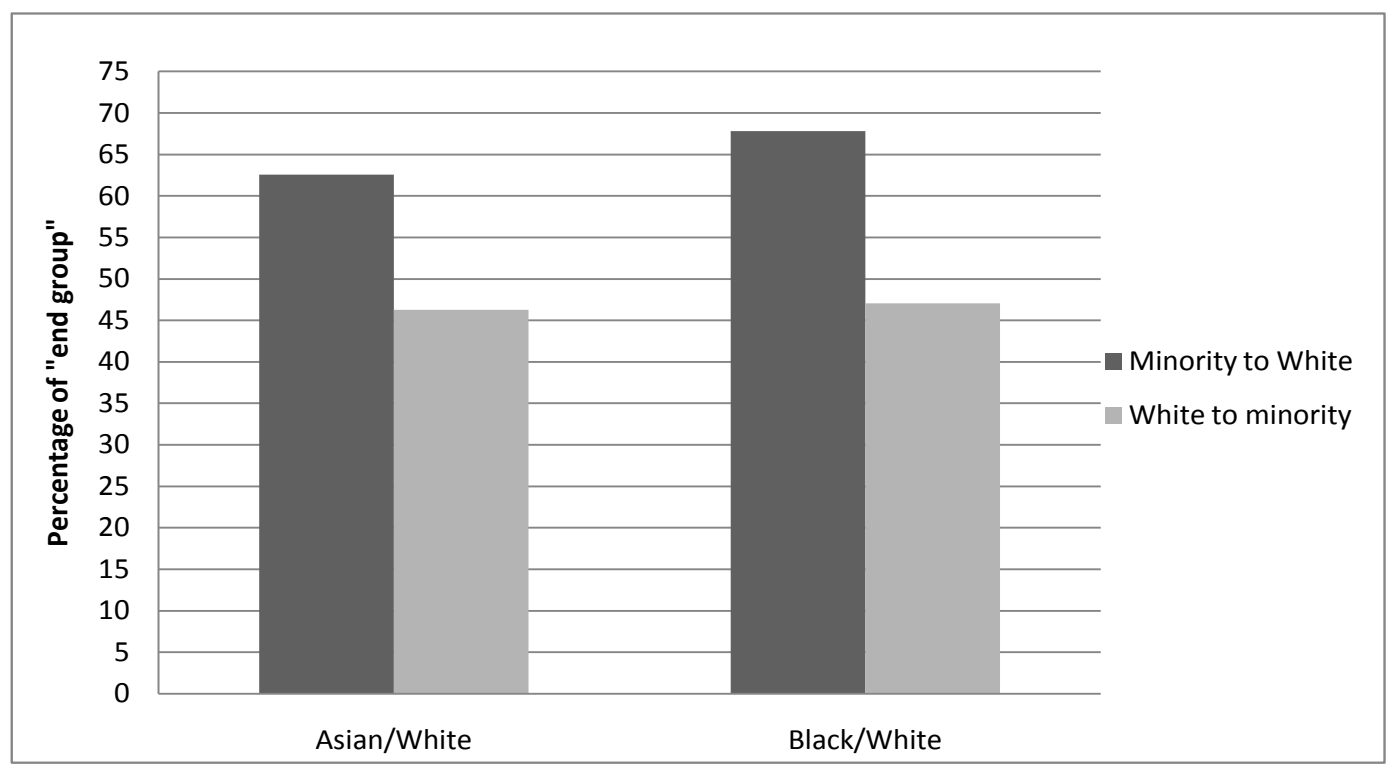

Figure 6. Percentage of the end group (i.e., White for "minority to White” trials and Asian or Black for "White to minority" trials) a target had to be to be perceived as a member of that group. 


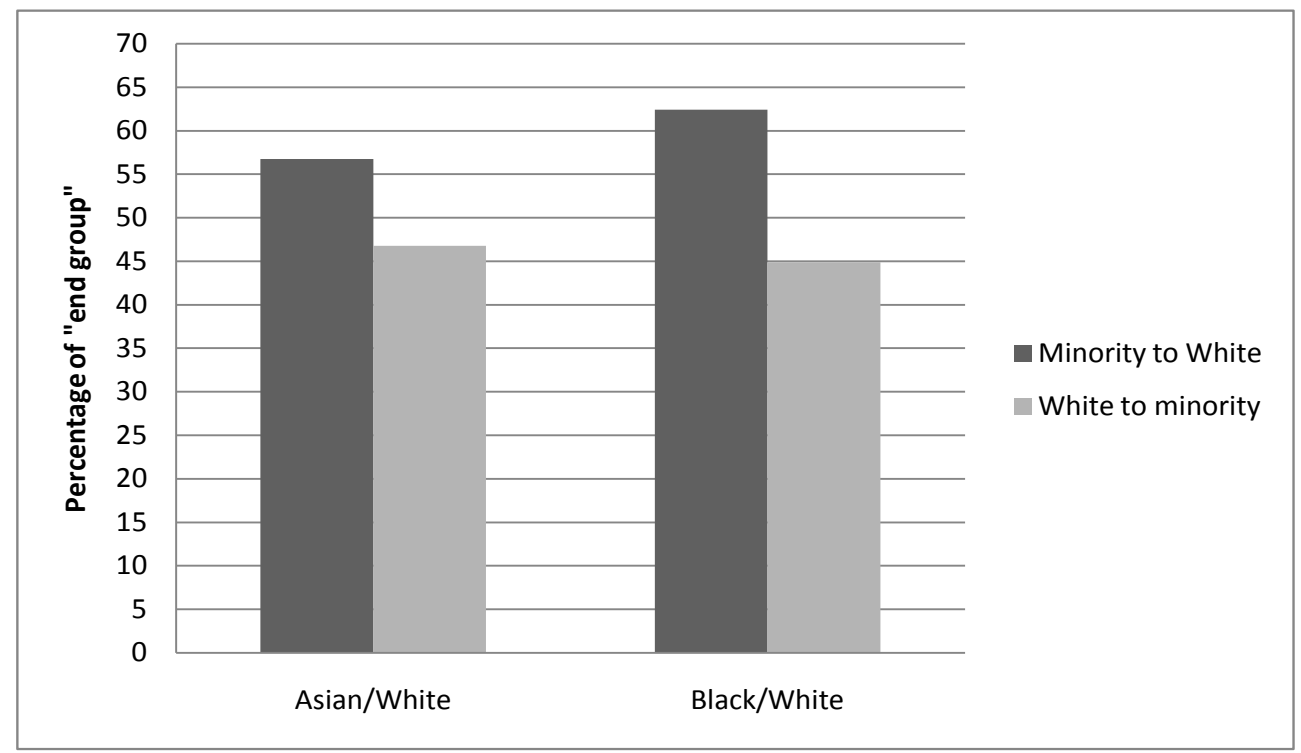

Figure 7. Percentage of the end group (i.e., White for "minority to White" trials and Asian or Black for "White to minority" trials) a target had to be to be perceived as a member of that group. 
${ }^{1}$ Other work has focused on neural (error-related potential) activity when presented with racially
ambiguous targets, moderators of racial categorization, and memory for mixed-race targets,
rather than on categorization of racially mixed targets as dominant or subordinate group
members per se (Corneille, Huart, Becquart, \& Bredart, 2004; Eberhardt, Dasgupta, \&
Banaszynski, 2003; Hugenberg \& Bodenhausen, 2004; Hutchings \& Haddock, 2008; MacLin \& Malpass, 2001; Pauker, Weisbuch, Ambady, Sommers, Adams, \& Ivcevic, 2009; WilladsenJensen \& Ito, 2006; 2008).

${ }^{2}$ At the time of data collection, we were primarily interested in the perceptions of dominant group members. However, as seen in Experiments 1 and 3, White and non-White participants do not seem to respond very differently.

${ }^{3}$ No other main or interaction effects were statically significant, although the three-way interaction between racial label, target race, and target sex was marginally significant $(F(1,18)=$ 3.67, $p=.07, r=.41)$. A simple effects analysis showed that while the hypodescent effect was strong and significant for half-Asian and Black male and female targets, the effect appeared to be stronger for male targets $(F(1,18)=8.92, p<.01, r=.58)$ than female targets $(F(1,18)=5.70$, $p<.05, r=.49)$ for Black-White targets, but stronger for female targets $(F(1,18)=9.54, p<$ $.01, r=.59)$ than for male targets $(F(1,18)=5.31, p<.05, r=.48)$ for Asian-White targets. However, further probing showed that the acceptance of the White label and minority label was not significantly different for male and female targets within each biracial group (e.g., Asian label was accepted equally for half-Asian males and females). Thus, this marginally significant three-way interaction did not imply differential use of the minority labels or the White label as a function of target gender for Asian-White or Black-White targets.

${ }^{4}$ While the dependent variables in Experiment 1 and 2 were somewhat different, and thus not directly comparable, we regard the finding of stronger effect sizes in Experiment 2 to be an important reason for using a speeded response task.

${ }^{5}$ See footnote 2 .

${ }^{6}$ We conducted the same analysis with participant race (i.e., White vs. non-White) as a covariate. It did not significantly interact with any effects, and will therefore not be discussed further.

${ }^{7}$ Our within subjects design allowed for the possibility that participants would attempt to memorize the point at which they decided the target changed from one racial category to the other when morphing in one direction, and subsequently indicate a race change at the same point when morphing in the opposite direction. However, this would not account for the hypodescent effect, as participants were randomly assigned to receive either the minority to White morphs first, or the White to minority morph first. We also compared responses from participants who received the Asian to White morph first to those who received the White to Asian morph first, in effect creating a between-subjects design. This yielded a similar hypodescent effect, with those who received the Asian to White morph first requiring the target to be $62.0 \%$ White before indicating that the target was White. Participants who received the White to Asian morph first required the target to be $46.5 \%$ Asian before indicating the target was Asian. This morph direction effect was significant $(t=-5.43, p<.001)$. Looking at the Black-White morphing tasks in the same between-subjects manner, we also get a hypodescent effect, with participants who received the Black to White morph first requiring the morph to be $66.5 \%$ White before indicating the target was White. Participants who received the White to Black morph first only required the 
target to be $43.5 \%$ Black before considering the target to be Black. This morph direction effect was also significant $(t=5.96, p<.001)$.

${ }^{8}$ We again conducted this analysis with participant race (i.e., White vs. non-White) as a covariate, and again did not find any interaction between race and our effects.

${ }^{9}$ We looked at the hypodescent effect between-subjects as well, as we did for experiment 3A. Again, a similar directional hypodescent effect was observed for Asian-White targets (52.9\%

White to be considered White, 42.0\% Asian to be considered Asian; $t=-3.11, p<.01$ ) and BlackWhite targets (61.1\% White to be considered White, $44.2 \%$ Black to be considered Black; $t=$ 4.43, $p<.001)$.

${ }^{10}$ One exception was in Experiment 1, when White respondents rated a quarter-Black-White target as relatively more White than non-Whites. In the speeded categorization task in Experiment 3B, Whites categorized a half-Black-White target as White more often than nonWhites. While these were interesting findings, they were deviations from our general finding of no difference between White and non-White respondents. These aberrations are difficult to explain in our current studies, but future research examining antecedents of hypodescent among Whites and non-Whites may shed light on why there are differences, if they appear. 